DR. BETTINA BELLOCQ (Orcid ID : 0000-0001-7643-7303)

Article type : Research

\title{
Contribution of cooking and drying o the structure of couscous grains made from durum wheat semolina
}

\author{
Bettina Bellocq, Thierry Ruiz and Bernard Cuq
}

UMR IATE 1208 CIRAD/INRA/Montpellier SupAgro/Université de Montpellier, 2 Place Pierre Viala, 34060 Montpellier Cedex 5, France

bernard.cuq@supagro.fr

\begin{abstract}
Background and objectives: During the processing of couscous grains of durum wheat semolina, the steam cooking and the drying stage help to strengthen the structure and to reach the end-properties of the product. The objective of the present work-was to investigate the physico-chemical mechanisms generated during the steam cooking stage, under different water contents, and the drying stage, under different temperatures.
\end{abstract}

Findings: The physico-chemical characteristics of couscous grains (size, shape, compactness, water content, extent of starch gelatinization, microstructure and texture) were measured during processing. These mechanisms are promoted by the high temperatures during processing under different conditions of water contents and by the water transfer. The mechanisms were discussed in regards to the state diagram of the wheat components and the hydrotextural diagram.

Conclusions: During the steam cooking and the drying stages, the grains remain saturated by interstitial water, which means that the deformation mechanisms of the grains compensated the variations of the water content.

This article has been accepted for publication and undergone full peer review but has not been through the copyediting, typesetting, pagination and proofreading process, which may lead to differences between this version and the Version of Record. Please cite this article as doi: $10.1002 /$ cche. 10078

This article is protected by copyright. All rights reserved. 
Significance and novelty: An analytical drying model describes the kinetics of average water contents during the first part of the drying stage and allows modelling the changes in compactness and the subsequent changes in diameter for the agglomerates of couscous grains.

Keywords - Steam cooking; drying; couscous grains; phase diagram; hydrotextural approach

\section{Introduction}

Couscous grains are a food product that can be consumed in different ways such as "taboulé salad" or traditional "couscous meal". The Codex alimentarius (Codex Standard 202-1995) defined "couscous" as the product prepared from coarse and fine durum wheat semolina (Triticum durum) that are agglomerated by adding potable water and then undergo physical and thermal treatments. The simplicity of preparing the couscous, its high nutritional value and its cheapness are the main reasons behind its large popularity.

Production of the couscous grains follows four successive unit operations: wet agglomeration, rollingsieving, steam cooking, and drying (Abecassis, Cuq, Boggini, \& Namoune, 2012; Bellocq, Ruiz, Delaplace, Duri, \& Cuq, 2017; Ruiz, Rondet \& Cuq, 2014). Durum wheat semolina and water are first mixed together to promote the wet agglomeration of the native semolina particles and form the wet agglomerates. The wet agglomerates are then rolled in a rotating screen drum to improve the structure of the grains and to select by size classification the fraction with diameter ranging between 1 and 2 $\mathrm{mm}$. The rolled agglomerates are then cooked using steam at $100^{\circ} \mathrm{C}$ to strengthen the structure and finally dried to reduce the water content and guaranty stability over the storage.

As a food product, the steam cooking is a critical stage during couscous grains processing, as it directly contributes to the digestibility and nutritional values to the final product (Abecassis et al., 2012). The steam cooking stage also significantly contributes to strengthen the cohesion of the couscous grains, by promoting biochemical links between the wheat components. The cooking stage induces a partial melting and merging of the semolina particles and transforms the wet agglomerates into more stable grains, in the sense where they are more plastic and less fragile. Several physicochemical changes are promoted by the steam cooking stage: the gelatinization of the starch granules, the formation of amylose-lipid complexes, and the insolubilisation of gluten proteins. These mechanisms allow generating physicochemical links between the semolina particles inside the grains. The liquid capillary bonds involved in the agglomeration stage to link the semolina particles are strengthened by these chemical changes. After the cooking stage, the extent of gelatinization of the starch granules measured by differential scanning calorimetry has been found between 50 and $60 \%$

This article is protected by copyright. All rights reserved. 
(Debbouz \& Donnelly, 1996). The intensity of the gelatinisation mechanisms is considered as a major determinant of the couscous use properties (Abecassis et al., 2012). After the gelatinization of the starch granules, the amylose chains are available and could take part to specific reactions with the lipid chains under high temperatures. The formation of the amylose-lipid complexes could contribute to strengthen the structure, to limit the stickiness after rehydration, and to reduce the retrogradation mechanisms during the storage. The insolubilisation of gluten proteins can be associated to crosslinking reactions with the formation of covalent bonds. Even if the proteins are not structured as a continuous network inside the couscous grains (in contrast with the structure of the durum wheat pasta), the crosslinking reactions could contribute to decrease the stickiness of the couscous grains after hydration (Abecassis et al., 2012). At the industrial scale, the steam cooking stage is conducted in continuous oven, at $100^{\circ} \mathrm{C}$ using steam at atmospheric pressure. The wet grains are layered on a perforated metallic surface. The thickness of the grain layer (about $20 \mathrm{~cm}$ ) requires about $15 \mathrm{~min}$ for the duration of the cooking stage to ensure the complete cooking of the grains. A slight increase of 5 to $10 \%$ of the water content of the grains is observed during the cooking stage. It is due to the condensation and the capillary absorption of the water molecules on the grains surface.

During the couscous grain processing, the final drying stage is a critical step to agree with the legislation and to ensure the microbiological and physicochemical stability by reducing the water activity. The principle of the drying of the couscous grains is an extraction of the water by phase change and entrainment in a convective stream of air, at controlled speed, temperature and relative humidity. The drying stage has to reduce the water content of the couscous grains below $13.5 \%$. The drying stage could contribute to the texturing mechanisms of the couscous grains through the possible compaction of the structure. The shrinkage phenomenon can be modulated by the plasticity of the granular matrix and the intra-granular arrangement of the grains (Ruiz et al., 2014). At the industrial scale, the drying stage is conducted in continuous drier at high temperature $\left(90-120^{\circ} \mathrm{C}\right)$, with a short residence time close to 15 to 30 minutes.

Although some scientific works have investigated the agglomeration stage (Barkouti, Daladonde, Rondet, \& Ruiz, 2014; Hafsa et al., 2015; Saad, Barkouti, Rondet, Ruiz, \& Cuq, 2011) and the rolling stage (Bellocq et al., 2017) during the processing of the couscous grains, the steam cooking stage and the drying stage have not yet really been investigated (Guezlane, Colonna, \& Abecassis, 1998). The objective of the present work is to experimentally investigate the physicochemical mechanisms at different scales (molecular and grain scales) that are promoted by the steam cooking stage and by the drying stage, as a function of the process conditions. The analyses of the kinetics of the changes of the physicochemical characteristics of the grains during the cooking stage and the drying stage will contribute to built relationships between the process parameters, physicochemical mechanisms and properties of the couscous grains of durum wheat.

This article is protected by copyright. All rights reserved. 


\section{Material and methods}

\subsection{Raw materials}

Durum wheat semolina of industrial quality (Panzani group, France) was used as raw material. Semolina was stored in hermetic containers at $4{ }^{\circ} \mathrm{C}$ until needed. Semolina was first characterized in triplicate using standardized methods. The water content of semolina $(14.8 \pm 0.08) \mathrm{g}$ water/100 g dry semolina) was determined according to the approved method 44-15A (AACC, 2000), by weighing after oven drying at $105^{\circ} \mathrm{C}$ for $24 \mathrm{~h}$. The characteristic values $\left(\mathrm{d}_{10}, \mathrm{~d}_{50}\right.$, and $\left.\mathrm{d}_{90}\right)$ of particle diameter of semolina were measured by a laser particle size analyser (Coulter TMLS 230, Malvern, England) at room temperature. The median value of particle diameter of semolina $\left(\mathrm{d}_{50}\right)$ was of $287( \pm 2) \mu \mathrm{m}$. The diameter span was $\left(\mathrm{d}_{90}-\mathrm{d}_{10}\right) / \mathrm{d}_{50}=1.51$. The semolina true density $(1.415 \pm 0.003)$ g.cm $\left.{ }^{-3}\right)$ was measured by using a nitrogen pycnometer. The total nitrogen content (TN) of semolina was determined by the Kjeldahl method, and the crude protein content $(12.44 \pm 0.04) \mathrm{g}$ proteins $/ 100 \mathrm{~g}$ dry semolina) was calculated according to TN-5.7 based on the AFNOR method V 03-750 (AFNOR, 2014).

\subsection{Agglomeration, rolling and classification processes}

The wet agglomeration process was conducted by using a horizontal low shear mixer. The mixing tank (30 cm length, $11.5 \mathrm{~cm}$ width, and $16.5 \mathrm{~cm}$ height) was composed of a horizontal shaft axe, positioned at $5.5 \mathrm{~cm}$ from the bottom of the tank, with 14 metal rotating paddle blades $(4 \mathrm{~cm}$ length, 2 $\mathrm{cm}$ width, and $7.5 \mathrm{~cm}$ gap between 2 blades). A sample of $780 \mathrm{~g}$ of semolina was first introduced in the mixer tank and mixed for $2 \mathrm{~min}$ at constant mixer arm speed (100 rpm) to equilibrate the temperature at $20^{\circ} \mathrm{C}\left( \pm 2^{\circ} \mathrm{C}\right)$. Water was then directly sprayed over the semolina under mixing at almost constant flow rate $\left(2 \mathrm{~g} . \mathrm{s}^{-1}\right)$, for a period of 65 or $110 \mathrm{sec}$ to reach the final water content (32.0 or $48.2 \mathrm{~g}$ water/100 g dry matter, respectively) by using a single-fluid atomizing system (Spraying Systems Co., France, ref. TPU 6501). After the water addition step, the mixture was stirred for 10 min to homogenize and promote the agglomeration mechanisms. The wet grains were then collected using a plastic bowl. The wet grains were then directly rolled and sieved over a column of 2 metallic sieves of decreasing mesh $(2.0$ and $0.9 \mathrm{~mm}$ ). The sieve column was manually shaken for $1 \mathrm{~min}$ at ambient temperature, to limit the possible breakage of the wet grains. The wet grains were collected between the $2 \mathrm{~mm}$ and the $0.9 \mathrm{~mm}$ sieves. A new wet agglomeration process was made for each cooking and drying experiment.

This article is protected by copyright. All rights reserved. 


\subsection{Cooking process}

Wet grains were spread as a thick $(3 \mathrm{~mm})$ layer over a stainless-steel plate and introduced inside the steam cooker (Ravant Chaudronnerie, France) with 20 litres chamber. They are then steamed during different times $(1,3,5$, or $10 \mathrm{~min})$ at $100^{\circ} \mathrm{C}$ under saturated steam flow $\left(20 \mathrm{~kg} \cdot \mathrm{h}^{-1}\right)$ at atmospheric pressure. After the cooking stage, the cooked grains were immediately collected. Each cooking process was made in triplicate.

\subsection{Drying process}

The cooked grains were then spread as a thin layer (about $5 \mathrm{~mm}$ that is approximately 5 agglomerate diameters), over seven stainless-steel grids and introduced inside the drying chamber of a pilot scale dryer (Afrem, Lyon, France). The grains were dried using a hot air stream at constant low relative humidity $(50 \%)$, at different temperatures $\left(50,70\right.$, or $\left.90^{\circ} \mathrm{C}\right)$, and for different times $(1,3,5,7,10,15$, or $20 \mathrm{~min}$ ). The dried grains were collected immediately after the drying stage and stored inside hermetic plastic cups until characterization. Each drying process was made in triplicate.

\subsection{Grains characterization}

\subsubsection{Water content}

The water content of the grains was determined on 3-5 g samples, by a drying method in an oven (RB 360, WC Heraeus GmbH, Hanau, Germany) at $105^{\circ} \mathrm{C}$ for $24 \mathrm{~h}$ (AACC Method 44-15A). The water content ( $w$ ) of grains ( $\mathrm{g} / \mathrm{g}$ dry matter) was calculated by using: $w=m_{w} / d_{m}$, where $m_{w}$ is the mass of water ( $\mathrm{g}$ ) and $d_{m}$ is the mass of dry matter $(\mathrm{g})$ in the sample. Mean values were determined from triplicate.

\subsubsection{Extent of starch gelatinization}

Modulated differential scanning calorimetry (DSC Q200, TA Instruments, New Castle, DE, USA) calibrated with indium, was used to determine the extent of starch gelatinization of the grains, compared to the native durum wheat semolina which is taken as reference. About $5 \mathrm{mg}$ of sample were placed in a DSC aluminium pan and $12 \mu \mathrm{L}$ of pure water were added with a micropipette. The pan was then sealed, reweighed, and allowed to stand for $1 \mathrm{~h}$ at room temperature. Analyses were performed from $30^{\circ} \mathrm{C}$ to $110^{\circ} \mathrm{C}$ at a heating rate of $10^{\circ} \mathrm{C} \cdot \mathrm{min}^{-1}$ using an empty pan as a reference. For each endotherm, the onset (To), peak (Tp), and conclusion (Tc) temperatures, and the gelatinization

This article is protected by copyright. All rights reserved. 
enthalpy $(\Delta \mathrm{H})$ were computed by using the TA Instruments analysis software. Experiments were carried out in triplicate. The starch gelatinization degree was determined by comparing gelatinization enthalpy $(\Delta \mathrm{H})$ of the sample, with the gelatinization enthalpy $\Delta \mathrm{HR}$ of the native semolina. The degree of starch gelatinization (\%) was calculated using: $\left(1-\frac{\Delta H}{\Delta H \text { semolina }}\right) \times 100$. Mean values were determined from triplicate.

\subsubsection{Compactness}

Samples of grains (about $1 \mathrm{~g}$ ) were used to determine the compactness, i.e. the solid volume fraction: $\phi=\rho_{s} / \rho_{S}^{*}$. The solid apparent density $\rho_{s}$ of the grains was calculated from the solid apparent density $\rho$ (measured using a hydrostatic balance with paraffin oil): $\rho_{s}=\rho /(1+w)$. The solid true density $\rho_{s}{ }^{*}$ was measured by using a nitrogen pycnometer (Ultrapyc 1200e, Quatachrom) after drying the agglomerates in an oven at $105^{\circ} \mathrm{C}$ for $24 \mathrm{~h}$. Mean values were determined from 2 measurements. We calculated the volumetric deformation: $\varepsilon=\left|1-\phi / \phi_{0}\right|$, with $\phi_{0}$ and $\phi$ respectively the initial and final compactness of the grains.

\subsubsection{Agglomerate strength}

The mechanical strength of the grains was determined by using a texture analyser (TA-HD Plus, Stable Micro Systems, UK). A $30 \mathrm{~kg}$ load cell was used with a compressive metallic cylindrical probe (35 mm diameter) operating at $0.1 \mathrm{~mm} \cdot \mathrm{s}^{-1}$. Experiments were conducted by characterizing the grains one by one. It was thus not possible to characterize a large number of grains and only restricted number of grains (about 5) having some homogeneity in their size was tested, to be statistically "representative" of the sample. The mechanical strength is defined as the measured force needed to compress one grain at $50 \%$ of its initial height. Mean values were determined from 5 measurements.

\subsubsection{Morphometric parameters}

The grains were mounted on glass slides. Images were taken by a DS-Ri1 camera (color mode RGB, 16 bits per channel, $1280 \times 1024$ pixels) mounted on an AZ100 macroscope (Nikon, JP) (magnifications from $\mathrm{x} 1$ to $\mathrm{x} 40$ ) in light transmission mode. For each slide position, series of 10-15 images with different focal planes were taken in order to compose an extended focus image (image composed of the sharpest pixels between the Z-series). In addition, mosaic images were assembled by reconstructing 4 x 4 extended focus images using the imaging software NIS-Elements (Nikon, JP)

This article is protected by copyright. All rights reserved. 
operating the AZ100 system. Image analyses were carried out with the software Fiji ${ }^{\circledR}$. The circularity shape factor is defined as the ratio of the perimeter of the silhouette $(\mathrm{P})$ and the circumference of a disk that has the same area (A) as the silhouette.

\subsubsection{Model fitting}

Apparent first order kinetics were experimentally observed to describe the changes of the physicochemical characteristics of the grains as a function of the time cooking or drying. We used a first order equation (Eq. 1) to describe the process-time dependence of experimental values. The Chapman model has been used by Bayram (2005) to describe the gelatinization mechanisms of durum wheat bulgur as a function of the cooking time. The function is able describing apparent exponential curves converging to a limit value.

$$
y=y_{0}+a\left(1-e^{-b x}\right)
$$

Where $\mathrm{a}$ and $\mathrm{b}$ are the model coefficients related to the final plateau value, and the rate of the changes, respectively. These coefficients were used to calculate the final plateau value $\left(y_{0}+a\right)$ and the time $(1 / b)$ in minute, which corresponds to a process characteristic time. The a and $\mathrm{b}$ coefficients were determined using the Excel 2011 solver (Microsoft, Redmond, USA) and the XLSTAT add-on (Addinsoft, Paris, France). Statistical analysis was carried out with XLSTAT at 95\% confidence level in order to check the relevance of model coefficients by Student tests and p-value. The coefficient of determination $\mathrm{R}^{2}$ was calculated to gauge the goodness of fit. The statistical significance of results was conducted using single factor analysis of variance (ANOVA) on our replicated data. Multiple comparisons were performed by calculating the least significant difference using Microsoft Excel 2010 , at a $5 \%$ significance level.

\section{Results}

\subsection{Impact of the cooking stage on the characteristics of the grains}

The present study investigated the physicochemical mechanisms promoted by the steam cooking stage, by first processing the wet grains at high initial water content $(0.48 \mathrm{~g} / \mathrm{g}$ dry matter). Before cooking, the grains were characterized by relative low value of compactness $(0.590 \pm 0.021)$ and can be described as relatively porous structures, with semolina particles still visible on their surface. The 
initial level of apparent starch gelatinization has been measured by DSC to $24.9 \%( \pm 3.7 \%)$ before the cooking stage.

During the first minute of steam cooking, the water content of the wet grains rapidly increases (from 0.48 to $0.53 \mathrm{~g} / \mathrm{g}$ dry matter) (Fig. 1a). The maximum value of the water content (close to $0.58 \mathrm{~g} / \mathrm{g}$ dry matter) is reached after 5 minutes of cooking. On the other hand, the values of compactness decrease during the first minute of cooking to reach a constant value close to 0.544 (Fig. 1b). The diameter of the wet grains increases (from 1630 to $2150 \mu \mathrm{m}$ ) regularly with the cooking time due to expansion mechanisms (Fig. 1c). No significant changes were observed in the shape of the wet agglomerates, with constant values of circularity close to 0.540 (Fig. 1d). The swelling of the grains, due to the water transfer, is isotropic and leads to $8.4 \%$ of volumetric deformation. The extent of starch gelatinization increased rapidly during the cooking and reached $100 \%$ after 3 min (Fig. 2), which is different to the results observed by Debbouz \& Donnelly (1996). The microstructure of the wet grains is observed at different times of the cooking stage (Fig. 3). The native semolina particles are poorly visible at the surface of the grains and seem to be partly jammed and glued to each other.

A first order equation (Eq. 1) was used to describe the kinetics of the physicochemical changes induced by the steam cooking stage (Fig. 1-2). The model is well adapted (with $\mathrm{R}^{2}>0.979$ ) to describe the cooking stage (Table 1), except for the changes of the values of diameter (with $\mathrm{R}^{2}=$ 0.843 ) and circularity (with $R^{2}=0.589$ ). Almost similar calculated values of the characteristic times $(1 / \mathrm{b}$ values) are found (between 1.42 and $1.67 \mathrm{~min})$ when describing the changes in water content, compactness, and degree of starch gelatinization as a function of the cooking time. These results suggest functional links between the water absorption of the grains, the physicochemical changes of the wheat starch through gelatinization mechanisms, and their impact on the grain structure (compactness and diameter).

\subsection{Influence of the initial water content of the wet grains}

The impact of the initial water content of the wet grains on the physicochemical changes induced by the steam cooking stage is evaluated by comparing wet grains at different initial water contents $(0.32$ or $0.48 \mathrm{~g} / \mathrm{g}$ dry matter). The initial values of the physicochemical characteristics of the wet grains at low water content $(0.32 \mathrm{~g} / \mathrm{g}$ dry matter) before the steam cooking stage are significantly different from those measured for the grains at high water content $(0.48 \mathrm{~g} / \mathrm{g}$ dry matter $)$, with significant lower values of average size, compactness, and circularity (Fig. 1). On the other hand, no difference was observed between the values of extent of starch gelatinization, which remain low and close to $25 \%$.

This article is protected by copyright. All rights reserved. 
The steam cooking stage of the wet grains at low water content ( $0.32 \mathrm{~g} / \mathrm{g}$ dry matter) seems to induce almost similar physicochemical reactions, than those previously observed when considering the grains at high water content $(0.48 \mathrm{~g} / \mathrm{g}$ dry matter). Almost similar shapes of the experimental curves as a function of the cooking time are observed (Fig. 1-2). The observed gaps between the initial measured values of water content (Fig. 1a), compactness (Fig. 1b), average size (Fig. 1c), and circularity (Fig. 1d) remain almost constant over the time of steam cooking. In addition, the curves of the extent of starch gelatinization are almost superimposed (Fig. 2). The initial water content of the wet grain does not influence the type and rate of the physicochemical mechanisms induced by the steam cooking stage. It only influences the final value of water content and compactness at the end of the cooking stage. No change is observed for the extent of starch gelatinization, which reaches maximum value after 5 min of cooking.

The first order equation is also well adapted $\left(\mathrm{R}^{2}>0.961\right)$ to fit the kinetic of physicochemical changes that occurred during the cooking stage of the wet grains at low initial water content (Table 1), except for the values of circularity and diameter $\left(\mathrm{R}^{2}<0.624\right)$. The calculated values of the characteristic times $(1 / b)$ of the changes in water content, compactness, and extent of starch gelatinization remain close to $1.5 \mathrm{~min}$ (ranging between 1.33 and $1.67 \mathrm{~min}$ ). Almost similar characteristic times are thus found to describe the physicochemical reactions induced in the wet grains of durum wheat semolina regardless of their initial water content. The initial water content controls the final values $\left(y_{0}+a\right)$ of water content, diameter, circularity, and compactness.

\subsection{Impact of the drying stage on the characteristics of the grains}

Immediately after the steam cooking stage, the cooked wet grains are introduced in the drier to conduct the drying stage. The cooked grains are characterized by high water content $(0.55 \pm 0.04 \mathrm{~g} / \mathrm{g}$ of dry matter), compactness $(0.497 \pm 0.004)$, and maximum extent of starch gelatinization (close to 100\%) (Fig. 1 and 2).

The physicochemical mechanisms induced by the drying stage are first described when considering the drying at $50^{\circ} \mathrm{C}$ (Fig. 4). During the first minutes, rapid changes are observed concerning water content (Fig. 4a) and compactness (Fig. 4b) that reach constant values $(0.16 \mathrm{~g} / \mathrm{g}$ of dry matter and 0.812 , respectively) after only $10 \mathrm{~min}$ of drying. In addition, quasi-linear slight decrease in the values of the average size (Fig. 4c) and a gradual increase in the values of the mechanical strength are measured (Fig. 5). The values of circularity do not seem to be affected by the drying (Fig. 4d). It indicates that the shrinkage is isotropic and leads to $39 \%$ of volumetric deformation.

This article is protected by copyright. All rights reserved. 
No stationary phase at the beginning of the drying stage is observed, as the values of water content and compactness start instantly to change quickly. The mechanisms of heat exchanges inside the grains are enough quick to allow the wet grains to equilibrate rapidly with the drying temperature without stationary phase. This is partly due to the small diameter (between 1 and $2 \mathrm{~mm}$ ) and circular shape of the wet grains, which favour the heat transfer. Heat transfers are not limiting factors. The time to reach the equilibrium temperature into the centre of the grain (less than $1 \mathrm{~min}$ ) has been estimated using Eq. 2 in the case of heat transfer by conduction in a variable regime with a medium at uniform temperature, with Biot number $<0.1$ (Jannot, 2012).

$$
\frac{T-T_{0}}{T_{i}-T_{0}}=\exp (- \text { Biot. Fourier })=\exp \left(-\frac{h D t}{\lambda L}\right)
$$

Where $\mathrm{h}=10^{1} \mathrm{~W} \cdot \mathrm{m}^{-2} \cdot \mathrm{K}^{-1}$, is the order of magnitude of the coefficient of forced convection of the air at a low flow rate $\left(2 \mathrm{~m} \cdot \mathrm{sec}^{-1}\right)$ (Whitelaw, 1997); $\lambda=0.184 \mathrm{~W} \cdot \mathrm{m}^{-1} \cdot \mathrm{K}^{-1}$, is the thermal conductivity of the durum wheat (Tavman, 1998), $\mathrm{D}=1.410^{-4} \mathrm{~m}^{2} \cdot \mathrm{sec}^{-1}$, is the thermal diffusivity of the durum wheat (Bahrani, 2013); $\mathrm{t}$ is the time (sec) and $\mathrm{L}$ is the characteristic length of the couscous grains, considered as a sphere with a rayon close to $0.7510^{-3} \mathrm{~m}$.

Before the drying stage, the semolina particles are not visible at the surface of the cooked grains (Fig. 6). They are mostly jammed and glued to each other inside the grain structure. The drying stage induces a slight decrease in the diameter of the grains by shrinkage mechanisms (Fig 4b).

The first order equation is well adapted $\left(\mathrm{R}^{2}>0.912\right)$ to fit the kinetics related to the changes of the water content and compactness of the wet grains during the drying (Fig. 4 and Table 2). On the other hand, the model is not adapted to describe the changes of diameter, mechanical strength, and circularity $\left(\mathrm{R}^{2}<0.332\right)$. Almost similar calculated values of the characteristic times $(1 / \mathrm{b})$ are found for describing the changes in water content (4.4 $\mathrm{min})$ and compactness (4.3 $\mathrm{min})$ during drying. These results also suggest functional links between the water desorption of the grain and the changes of the grain structure (compactness and diameter).

\subsection{Influence of the drying temperature}

The impact of the drying temperature $\left(50,70\right.$, or $\left.90^{\circ} \mathrm{C}\right)$ is evaluated on the physicochemical changes induced by the drying stage. The drying stage of the grains at 70 or $90^{\circ} \mathrm{C}$ seems to induce almost similar physicochemical reactions than those previously observed at $50^{\circ} \mathrm{C}$. Almost similar shapes of the drying kinetics are observed at the different temperatures (Fig. 7-8). Slightly higher rates in the changes of water contents (Fig. 7a) and compactness (Fig. 7b) are observed. Increasing the drying

This article is protected by copyright. All rights reserved. 
temperature at 70 to $90^{\circ} \mathrm{C}$ induces similar physicochemical reactions than those previously observed at $50^{\circ} \mathrm{C}$. We also noticed that increasing the drying temperature (from 50 to $90^{\circ} \mathrm{C}$ ) induces a slight decrease of the final water content (from 0.16 to $0.09 \mathrm{~g} / \mathrm{g}$ dry matter) and a slight increase of the final compactness (from 0.815 to 0.872 ). The effect of the drying temperature on the measured values of diameter and circularity is not significant.

Whatever the drying temperature, the first order equation is well adapted $\left(\mathrm{R}^{2}>0.900\right)$ to describe the physicochemical changes of water content and compactness (Table 2). Almost similar characteristic times (between 3.5 and 5.9), are found to describe the physicochemical mechanisms induced by the drying at the different temperatures, which could be attributed to functional links between the water desorption and the changes in the compactness and diameters of the grains.

\section{Discussion}

The present study investigated the functional roles of the two hydrothermal treatments, i.e. the steam cooking stage and the drying stage, during processing of the couscous grains of durum wheat. We described the impact of the thermo-hydro-mechanical process conditions on the wheat components and granular characteristics (Cuq, Mandato, Jeantet, Saleh, \& Ruiz, 2013). The high temperatures and the different conditions of water contents impact the mechanisms of water transfers, which act on the compactness of the porous grains.

The calculation of the characteristics times of the changes on the physicochemical properties of the grains induced by the steam cooking stage and the drying stage, by using a first order model (Tables 1-2), improves the understanding of the mechanisms.

During the cooking stage, the characteristic times of the changes of water content, compactness, diameter, and starch gelatinization are quite similar (1.3 - $1.6 \mathrm{~min}$ ) regardless of conditions (Table 1). The maximum degree of starch gelatinization $(>80 \%)$ was reached after only 3 min of cooking, whatever the initial water content of the grains (Fig. 1). The final values of water content, compactness, and diameter depend on their initial values before cooking (Fig. 1). The steaming cooking stage increases the water content of the grains $(+10 \mathrm{~g} / \mathrm{g}$ dry matter). The swelling, due to water transfer inside the grains, leads to increase their diameter $(+0.8 \mathrm{~mm})$ and to decrease their compactness (-0.07). The values of circularity are not significantly affected by the cooking stage (Fig. 1), even if we observe a slight increase of circularity probably due to the isotropic swelling.

During the drying stage, the characteristic times of the changes in water content, compactness, and mechanical strength are quite similar (3.5 - $6.0 \mathrm{~min}$ ), whatever the temperature of drying (Table 2). During the drying, the diameter values decrease and the compactness values increase. These are due 
to the shrinkage mechanisms, which are induced by the water extraction. The values of circularity are not affected by the drying stage (Fig 4).

We demonstrate a significant effect of the drying temperature on the mechanisms. An increase in the drying temperature (from 50 to $90^{\circ} \mathrm{C}$ ) induced slight decreases of the water content and increases of the compactness of the grains (Fig 7-8).

The changes in the characteristics of the grains during the successive stages of steam cooking and drying are promoted by the heat treatments of the grains at different water contents, and by the mass transfers due to water exchanges with the surrounding atmosphere. We have calculated that the mechanisms of heat transfer inside the grains are faster than mass transfers and the deformation, so, we consider the temperature of the grains uniform and at equilibrium with the process temperature. During the steam cooking stage, the increase in water content of the grains is due to water vapour absorption by the wheat components under saturated humidity conditions and to the water condensation at the surface of the grains (Ruiz et al., 2014). During the drying stage, the decrease in water content of the grains is due to water vapour desorption due to the low value of ambiant relative humidity. The final values of water content can be related to the water desorption isotherms of the wheat components of durum wheat semolina.

The description of physicochemical mechanisms involved in the couscous grain formation can be carried out using the concept of state diagram for durum wheat semolina (Abecassis et al., 2012). State diagram is built from the knowledge of the changes in physical properties of the main wheat components, starch and proteins, as a function of water content and temperature (Cuq \& Abecassis, 2003). The physical approach is based on the description of reactivity of the wheat macromolecules as a function of their water content and temperature (Fig. 9). The state diagram defines the conditions of water content and temperature in which occurs the glass transition of amorphous components (proteins and starch chains), the gelatinization of starch granules, and the thermal reticulation of the wheat proteins.

Starting from native semolina, the first stages of agglomeration and rolling of the particles are conducted to generate the wet agglomerates with high water content. The hydration of the particles allows the passage over the glass transition for the wheat components, starch and proteins. The steam cooking stage generates a rapid increase in the temperature until $100^{\circ} \mathrm{C}$ and a slight subsequent gradual increase in water content. During the steam cooking stage, the process conditions then allow the gelatinization of the starch granules and the reticulation of the wheat proteins.

From all the experimental values measured during the cooking stage, the extent of starch gelatinization has been plotted as a function of the measured water content (Fig. 10). The starch gelatinization reached at $80 \%$ after 3 minutes of cooking with a water content close to $0.4 \mathrm{~g} / \mathrm{g}$ dry

This article is protected by copyright. All rights reserved. 
matter. This result is consistent with the state diagram of durum wheat components (Fig. 9), where the minimal value of water content required to promote the gelatinization of the starch granules is about $0.40 \mathrm{~g} / \mathrm{g}$ dry matter. Due to the high initial water content of the wet agglomerates and the appropriated rate of heat transfer, the gelatinization mechanism can occur rapidly during the steam cooking stage. The increase in the water content during cooking favours the progress of the reaction.

At the beginning of the drying stage, the water content and the temperature are still high enough to continue the reactions of starch gelatinization and protein reticulation. This period is short as the decrease in water content is rapid (Fig. 4). The wheat components are still over the glass transition curve and thus display a rubbery plastic behaviour. The final stage of cooling conducts to the final couscous grains with the wheat component in a glassy rigid state.

The changes in the characteristics of the grains during the successive stages of steam cooking and drying are also impacted by the mass transfers due to the water exchanges with the surrounding atmosphere. The impact of process parameters during the successive steam cooking and drying stages on the values of compactness and water content are discussed by using the hydrotextural diagram (Rondet, Rundgsiyopas, Ruiz, Deladonde, \& Desfours, 2009; Ruiz, Deladonde, \& Desfours, 2011) (Fig. 11). This phase diagram is based on the relations of volumes and masses conservation between the components of a wet granular medium and gives a global representation to depict the hydric and textural state in order to follow their evolutions when process stresses are applied (mixing stress, cooking rate, drying rate, etc.). It is limited in its upper part by the saturation curve, which represents the maximum water content that a medium of a given constant compactness can contain. Under this curve, unsaturated states result of granular, liquid and gaseous arrangements. The initial wet agglomerates generated by the agglomeration - rolling process are located on the saturation curve, as the porous grains are saturated by water (Fig. 11). During the steam cooking stage, the increase in water content of the grains is concomitant with a decrease of their compactness. It respects a balance of the volumes (Fig. 11a). During the drying stage, the decrease in water content of the wet grains is concomitant with an increase of their compactness (Fig. 11b). The saturation relation (Eq. 3) links the water content and the compactness of the grains.

$$
\phi^{-1}=1+d_{s}^{*} w
$$

where $d_{s}^{*}$ is the ratio of the true density of the solid phase and the true density of water. These relationships are similar to those obtained due to the behaviour of the wet agglomerates of durum wheat semolina during the agglomeration process (Rondet, Deladonde, Ruiz, \& Desfours, 2010; Barkouti et al., 2014) or the rolling stage (Bellocq et al., 2017).

This article is protected by copyright. All rights reserved. 
The steam cooking stage and the drying stage impact the hydrotextural parameters of the wet grains. Whatever the process parameters the grains generated in this study are found to be close to the saturated state (Fig. 11). The changes in the diameter of the grains are coupled with changes in water content and compactness, so that the grains remains saturated. The swelling of the grains during the cooking stage and the shrinkage of the grains during the drying stage are conducted without gaseous phase apparition, because of the plasticization of the components above the glass transition and the plasticity of the matter. The ability of the durum wheat matter to be deformed during the steam cooking stage and the drying stage is not to be a limit phenomenon. The range of variation of the compactness is essentially due to the particle arrangement under water transfers.

The measured changes in the mechanical strength (compression force) of the grains during the drying stage (Fig. 5 and 8) can be plotted as a function of their water contents (Fig. 12). During the drying, the decrease in water content induces an increase in the mechanical strength. We observed an abrupt transition from low to high values of apparent strength at a critical level of water content. The values of mechanical strength seem to reach a maximum constant value at low water content. Wet grains behave as a visco-plastic and soft product. Dried grains behaves as a rigid product. A sigmoid curve characterizes the relationship between the apparent strength and the water content of the grain. The changes in mechanical strength as a function of water content (measured at $20^{\circ} \mathrm{C}$ ) can be described by using the logistic model (Eq. 4) adapted to describe sigmoid curves (Cuq, Gonc, Franc, \& Vareille, 2003b).

$$
Y(w)=\frac{Y_{H}-Y_{L}}{\left(1+\exp \frac{W-w_{i}}{A}\right)}+Y_{L}
$$

Where $\mathrm{Y}$ is the calculated mechanical strength, $\mathrm{w}$ is the water content ( $\%$ dry basis), $\mathrm{Y}_{\mathrm{H}}$ is the calculated maximum value of property, $\mathrm{Y}_{\mathrm{L}}$ is the calculated minimum value of property, $\mathrm{w}_{\mathrm{i}}$ is the water content ( $\%$ dry basis) at the inflection point of the sigmoid curve and $\mathrm{A}$ is a constant $(\%$ dry basis), which characterizes the spread of the transition from high to low values of mechanical property. The logistic model fitted well experimental data $\left(\mathrm{R}^{2}=0.95\right)$, with the following calculated values of parameters: $A=4.5 \%, w_{i}=25 \%, Y_{H}=22 \mathrm{~N} ; Y_{L}=0.5 \mathrm{~N}$. (Table 2). Cuq et al. (2003b) explained that the effects of water content on the mechanical strength of dried grains of couscous could be interpreted using the concepts of plasticization and glass transition. The transition of the mechanical properties may be explained by the glass transition of the hydrophilic amorphous components of wheat semolina. The molecular mobility is enhanced by an increase in temperature (i.e., thermal plasticization) or water content (i.e., water plasticization). The critical water content at the glass transition of mechanical strength of dried grains at ambient temperature is almost similar with the glass transition of durum wheat semolina (Cuq, Abecassis, \& Gulbert, 2003a; Cuq \& IcardVernière, 2001). 
By considering rapid heat transfer inside the grains, three mechanisms contribute to the drying phenomena: (i) the liquid evaporation at the surface (phase change), (ii) the liquid transport in the product (diffusion in the pores network) and (iii) the deformation of the product (mechanical shrinkage), which involves a modification of the local texture. The liquid transfer is localized at the level of the drying air/water interface. As long as the product remains saturated, this interface is located at the periphery of the grain. This interface includes the area of the peripheral capillary meniscus and the contribution of the water films, which wet the particles of the edge and between the capillary meniscus. Due to the difficulty of estimating this area and its evolution during drying, it is often assimilated to the geometric surface of the product. In the case of grains, it could be a simplified a quasi-sphere in a first approximation. This transfer, which is well described by the double layer theory, found limitation of its rate from the kinetic of molecular transport into the diffusional layers. The boundary conditions (the gaseous diffusion layer and the drying atmosphere) are the major factors controlling the transfer during the isenthalpic period, characterized especially by a constant flux. This period is so-called a period at constant rate. These transfer conditions are induced by the process parameters which controlled the drying atmosphere characteristics. They are fixed at the scale of the reactor. When these process parameters are constant, the end of this drying period is due to the limitation by another kinetic phenomenon, which is expressed "inside the product": desaturation, transport of limiting water, etc. On the other hand, the water transfer induces a mechanical shrinkage (case of a deformable material), and it is necessary to take into account the evolution of the exchange surface in order to correct the value of the flux by the loss of surface area (case of the model used).

The transport of water inside the product is linked to the physical nature of the microstructure of the material: liquid conduction within a micro or macro-porous network, liquid diffusion within a nanoporous network or a gel, gaseous diffusion, etc. The kinetic of migration of the water towards the drying surface is related to the gradients of chemical potential of water developed during the drying. The transport properties (permeability, diffusion coefficient, etc.) modulate this rate. An evolution of the microstructure during the drying (case of chemical reactions or mechanical shrinkage) finds its dependence on the state parameters that describe it.

The deformation constitutes a mechanical relaxation over a thermo-hydro-mechanical load applied via the capillary pressure at each contact line. The product adapts itself to the stresses applied locally by the difference between the relative humidity of the drying atmosphere and the water activity. Its amplitude and intensity depend on $(i)$ the rheology of the product (and its evolution with the water content), (ii) the mechanical stress rate applied by the operating conditions, and (iii) its location as a function to the kinetic of transfer. 
An analytical model detailed in Rungsiyopas \& Ruiz (2018) allows describing the kinetics of average water content during the first part the drying stage $(<8 \mathrm{~min})$ at the product scale (Eq. 5) with a good agreement to our data ( $\mathrm{R}^{2}$ between 0.96 and 0.98 ) (Fig. 13).

$$
w(t)=w_{\text {init }}-d_{s}^{*-1} \phi_{\text {init }}^{-1}+\beta(t-\tau)^{3}
$$

Where $\beta$ and $\tau$ are two terms which take into account the dependence of the liquid/gas exchange rate by its relation with the product shape, assimilating in this paper as a sphere; $w_{\text {init }}$ and $\phi_{\text {init }}$ are respectively the initial water content and compactness of the agglomerate. The analytical model allows describing the water desorption until the hygroscopic limit of the product is reached. This hygroscopic limit depends both of the components of the product and transfer conditions induced by the process parameters.

By reporting the equation of the drying model (Eq. 5) in the saturation relation (Eq. 3) we can determine the kinetic of compactness. Moreover, considering that the circularity is still constant and by assimilating the agglomerate as a quasi-sphere, we can easily establish the kinetic of radius decreasing. We found by this way that this kinetic is quasi-linear with the time: $R \propto V^{\frac{1}{3}} \propto \phi^{\frac{1}{3}} \propto t$, and this result is confirmed by the experimental datas (Fig. 7c).

\section{Conclusion}

The paper investigated the physico-chemical mechanisms promoted by the steam cooking stage at different initial water contents $(0.32$ or $0.48 \mathrm{~g} / \mathrm{g}$ dry matter) and by the drying stage at different temperatures $\left(50,70\right.$, or $\left.90^{\circ} \mathrm{C}\right)$ during the processing of the couscous grains of durum wheat. We demonstrated significant effect on the water content, compactness, diameter, circularity, and starch gelatinization of the grains. The kinetics of the physicochemical changes were described using a first order model. The calculated values of characteristics times were used to discuss the mechanisms. The transfer of water into the granular matter appears to be the limiting phenomenon during the cooking stage. It promotes the expansion of the structure because of the granular plasticity and it leads to an increase in the diameter of the grains. The filling of the inter particle voids is due to the absorption of water. It also promotes the starch gelatinization. The initial water content does not impact the characteristic times of the water diffusion and starch gelatinization mechanisms. During the drying stage, the transfer of water is also the limiting phenomena. It promotes the compaction of the structure and decreases the diameter of the grains. As the grains remain on the saturation curve all along the process, we supposed that the variations of the compactness are essentially due to the arrangement of the internal structure. We used an analytical drying model to describe the kinetics of average water content during the first part of the drying stage at the product scale. Using this model and the

This article is protected by copyright. All rights reserved. 
saturation relation, we modelled the changes in compactness and the subsequent changes in diameter for the agglomerates of couscous grains.

\section{Acknowledgments}

The authors would like to thank the Agence Nationale de la Recherche (ANR-13-ALID-0002-01) for its financial support through the program "Dur Dur".

\section{References}

Abecassis, J., Cuq, B., Boggini, G., \& Namoune, H. (2012). Other traditional durum derived products. Durum Wheat: Chemistry and Technology, pp. 177-200.

Bahrani, S.A. (2013). Modification des propriétés physico-chimiques de l'amidon par procédés hydrothermiques: Contribution à l'étude des transferts couplés chaleur-masse. Thèse de doctorat. Université de La Rochelle.

Barkouti, A., Delalonde, M., Rondet, E., \& Ruiz, T. (2014). Structuration of wheat powder by wet agglomeration: Case of size association mechanism. Powder Technology, 252, 8-13.

Bayram, M. (2005). Modelling of cooking of wheat to produce bulgur. Journal of Food Engineering, 71, 179-186.

Bellocq, B., Ruiz, T., Delaplace, G., Duri, A. \& Cuq, B. (2017). Screening efficiency and rolling effects of a rotating screen drum used to process wet soft agglomerates. Journal of Food Engineering, 195, 235-246.

Cuq, B., Abecassis, J. \& Guilbert, S. (2003a). State diagrams to help describe wheat bread processing. International Journal of Food Science and Technology, 38, 759-766.

Cuq, B., Gonc, F., Franc, J. \& Vareille, L. (2003b). Effects of moisture content and temperature of spaghetti on their mechanical properties. Journal of Food Engineering, 59, 51-60.

Cuq, B. \& Icard-Vernière, C. (2001). Characterisation of glass transition of durum wheat semolina using modulated differential scanning calorimetry. Journal of Cereal Science, 33, 213-221.

Cuq, B., Mandato, S., Jeantet, R., Saleh, K., \& Ruiz, T. (2013). Agglomeration / granulation in food powder production. Handbook of Food Powders: Processes and Properties, Woodhead publishing, pp. 150-177.

This article is protected by copyright. All rights reserved. 
Debbouz, A. \& Donnelly, B.J. (1996). Process effect on couscous quality. Cereal Chemistry, 73, 668671.

Guezlane, L., Colonna, P., \& Abecassis, J. (1998). Effet des traitements hydrothermiques du couscous de blé sur les modifications physiques de l'amidon. Annales de l'Institut National Agronomique d'El Harrach, 19(1-2), 62-81.

Hafsa, I., Mandato, S., Ruiz, T., Schuck, P., Jeantet, R., Mejean, S., Chevallier, S., \& Cuq, B. (2015). Impact of the agglomeration process on structure and functional properties of the agglomerates based on the durum wheat semolina. Journal of Food Engineering, 145, 25-36.

Jannot, Y. (2012). Transferts thermiques. Support de cours de $2^{\text {ème }}$ année. Ecole des Mines de Nancy.

Ounane, G., Cuq, B., Abecassis, J., Yesli, A., \& Ounane, S.M. (2006). Effects of physicochemical characteristics and lipid distribution in Algerian durum wheat semolinas on the technological quality of couscous. Cereal Chemistry, 83, 377-384.

Rondet, E., Rundgsiyopas, M., Ruiz, T., Delalonde, M., \& Desfours, J.P. (2009). Hydrotextural description of an unsaturated humid granular media: Application for kneading, packing and drying operations. Kona Powder and Particle Journal, 27, 174-185.

Rondet, E., Delalonde, M., Ruiz, T., \& Desfours, J.P. (2010). Fractal formation description of agglomeration in low shear mixer. Chemical Engineering Journal, 164, 376-382.

Ruiz, T., Rondet, E., \& Cuq, B. (2014). La graine de couscous. De l'artisanat à la croissance fractale. Sciences Culinaires, Matière, Procédés, Dégustation, pp. 52-73.

Ruiz, T., Rondet, E., Delalonde, M., \& Desfours, J.P. (2011). Hydro-textural and consistency surface states of humid granular media. Powder Technology, 208, 409-416.

Rungsiyopas M., \& Ruiz T. (2018). Modelling of the shape effect on the drying shrinkage of wet granular materials. Chemical Engineering Research and Design, 132, 295-302.

Saad, M.M., Barkouti, A., Rondet, E., Ruiz, T., \& Cuq, B. (2011). Study of agglomeration mechanisms of food powders: Application to durum wheat semolina. Powder Technology, 208, 399-408.

Tavman, S. (1998). Measurement of effective thermal conductivity of wheat. International Communication Heat Mass Transfer, 25, 733-741.

Whitelaw, J.H. (1997). Convective heat transfer. International Encyclopedia of Heat and Mass Transfer, 237.

This article is protected by copyright. All rights reserved. 
Table 1.

Calculated values of the coefficients ( $\mathrm{a}$ and $\mathrm{b}$ ) and fitting quality parameters ( $\mathrm{R}^{2}$ and residual difference) of the first order equation used to describe the changes of the physicochemical characteristics of the wet grains of durum wheat semolina, as a function of the time of the steam cooking stage at different initial water contents ( 0.32 and $0.48 \mathrm{~g} / \mathrm{g}$ dry matter).

\begin{tabular}{llllllll} 
& $\begin{array}{llllll}\text { Initial water } \\
\begin{array}{l}\text { content }(\mathrm{g} / \mathrm{g} \\
\text { dry matter })\end{array}\end{array}$ & $\begin{array}{l}\text { Coef. } \\
\text { Water content }\end{array}$ & $\begin{array}{l}\text { Coef. } \\
\mathrm{b}\end{array}$ & $\begin{array}{l}\text { Plateau } \\
\text { value } \\
\left(\mathrm{y}_{0}+\mathrm{a}\right)\end{array}$ & $\begin{array}{l}\text { Characteristic } \\
\text { time } \\
(1 / \mathrm{b})\end{array}$ & $\mathrm{R}^{2}$ & $\begin{array}{l}\text { Residual } \\
\text { standard } \\
\text { difference }\end{array}$ \\
& 0.48 & 0.102 & 0.601 & 0.579 & 1.67 & 0.979 & 0.001 \\
\hline $\begin{array}{l}\text { Average } \\
\text { diameter }\end{array}$ & 0.32 & 3.43 & 0.040 & 5.06 & 25.23 & 0.507 & 0.541 \\
\hline Compactness & 0.48 & 2.22 & 0.052 & 3.46 & 19.33 & 0.843 & 0.366 \\
& 0.32 & -0.090 & 0.750 & 0.59 & 1.33 & 0.985 & 0.001 \\
\hline Circularity & 0.48 & -0.044 & 0.702 & 0.55 & 1.42 & 0.993 & 0.019 \\
& 0.32 & 0.098 & 0.056 & 1.03 & 1.58 & 0.624 & 0.002 \\
\hline $\begin{array}{l}\text { Starch } \\
\text { gelatinization }\end{array}$ & 0.32 & 0.068 & 0.056 & 0.611 & 17.82 & 0.589 & 0.007 \\
& 0.48 & 0.784 & 0.635 & 1.03 & 1.58 & 0.983 & 0.008 \\
\hline
\end{tabular}

This article is protected by copyright. All rights reserved. 
Table 2.

Calculated values of the coefficients ( $\mathrm{a}$ and $\mathrm{b}$ ) and fitting quality parameters $\left(\mathrm{R}^{2}\right.$ and residual difference) of the first order equation used to describe the changes of the physicochemical characteristics of the wet grains of durum wheat semolina, as a function of the time of the drying stage at different drying temperatures $\left(50,70\right.$, or $\left.90^{\circ} \mathrm{C}\right)$.

\begin{tabular}{|c|c|c|c|c|c|c|c|}
\hline & $\begin{array}{l}\text { Drying } \\
\text { temperature } \\
\left({ }^{\circ} \mathrm{C}\right)\end{array}$ & $\begin{array}{l}\text { Coef. } \\
\text { a }\end{array}$ & $\begin{array}{l}\text { Coef. } \\
\text { b }\end{array}$ & $\begin{array}{l}\text { Coefficient } \\
\mathrm{y}_{0}+\mathrm{a}\end{array}$ & $\begin{array}{l}\text { Coefficient } \\
1 / b\end{array}$ & $\mathrm{R}^{2}$ & $\begin{array}{l}\text { Residual sum } \\
\text { of square }\end{array}$ \\
\hline \multirow{3}{*}{ Water content } & 50 & -0.403 & 0.225 & 0.148 & 4.43 & 0.988 & 0.002 \\
\hline & 70 & -0.477 & 0.284 & 0.110 & 3.52 & 0.964 & 0.009 \\
\hline & 90 & -0.468 & 0.184 & 0.075 & 5.45 & 0.974 & 0.006 \\
\hline \multirow{3}{*}{ Compactness } & 50 & 0.321 & 0.233 & 0.818 & 4.29 & 0.986 & 0.001 \\
\hline & 70 & 0.356 & 0.273 & 0.853 & 3.66 & 0.982 & 0.002 \\
\hline & 90 & 0.380 & 0.184 & 0.879 & 5.10 & 0.974 & 0.004 \\
\hline \multirow{3}{*}{ Average diameter } & 50 & -3.50 & 0.010 & -1.35 & 100.00 & 0.332 & 0.467 \\
\hline & 70 & -0.431 & 100.00 & 1.72 & 0.010 & 0.104 & 0.719 \\
\hline & 90 & -0.108 & 100.00 & 1.99 & 0.010 & 0.203 & 0.104 \\
\hline \multirow{3}{*}{ Circularity } & 50 & -0.113 & 100.00 & 0.590 & 0.010 & 0.046 & 0.012 \\
\hline & 70 & -0.113 & 100.00 & 0.598 & 0.010 & 0.044 & 0.016 \\
\hline & 90 & -0.112 & 100.00 & 0.609 & 0.010 & 0.000 & 0.017 \\
\hline \multirow{3}{*}{$\begin{array}{l}\text { Mechanical } \\
\text { strength }\end{array}$} & 50 & 20.00 & 0.085 & 20.28 & 11.77 & 0.978 & 5.65 \\
\hline & 70 & 21.31 & 0.182 & 20.98 & 5.51 & 0.958 & 20.81 \\
\hline & 90 & 24.80 & 0.168 & 25.08 & 5.97 & 0.900 & 70.37 \\
\hline
\end{tabular}

This article is protected by copyright. All rights reserved. 


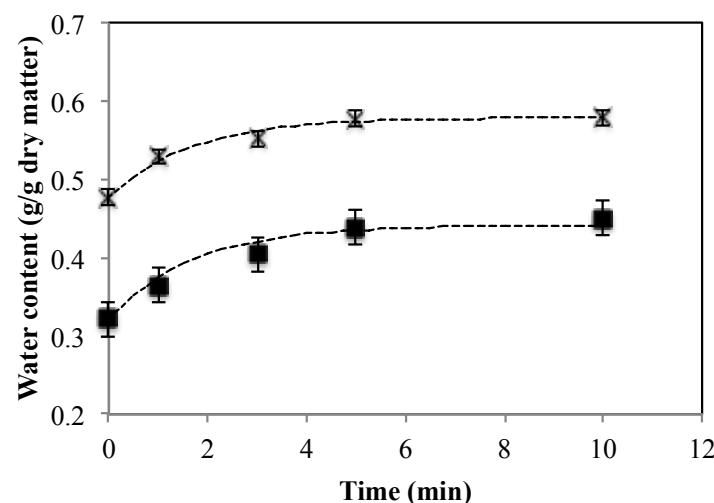

a)

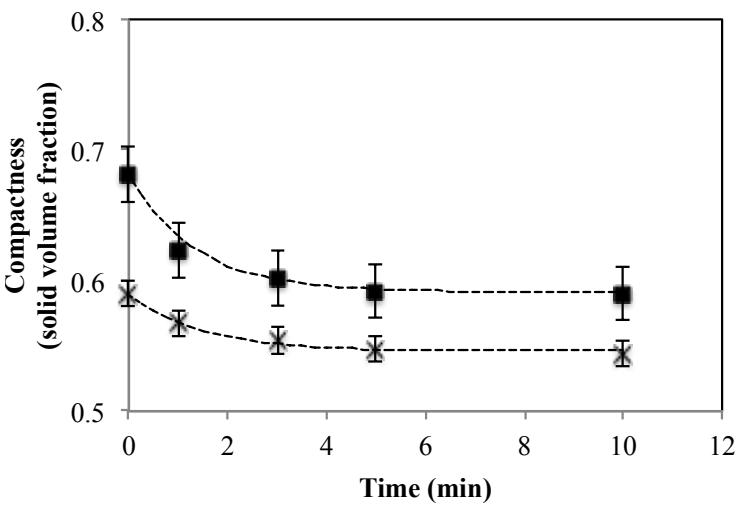

b)

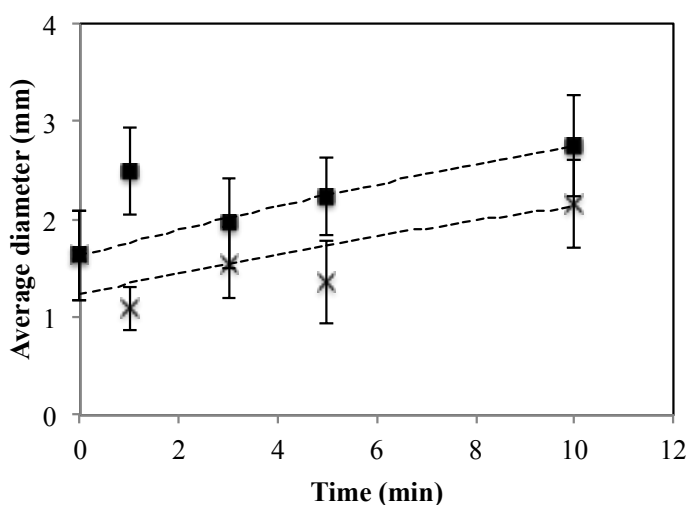

c)

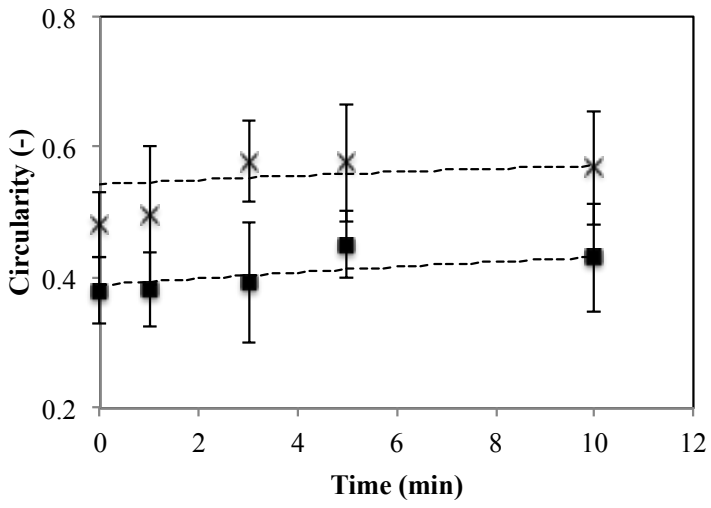

d)

Fig. 1. Changes in water content (a), compactness (b), average diameter (c), and circularity (d) of wet agglomerates of durum wheat as a function of the time of the cooking stage, at different initial water contents $(\boldsymbol{\square} 0.32 \mathrm{~g} / \mathrm{g}$ dry matter and $\times 0.48 \mathrm{~g} / \mathrm{g}$ dry matter). The dotted lines are the first order equation used to fit the experimental data.

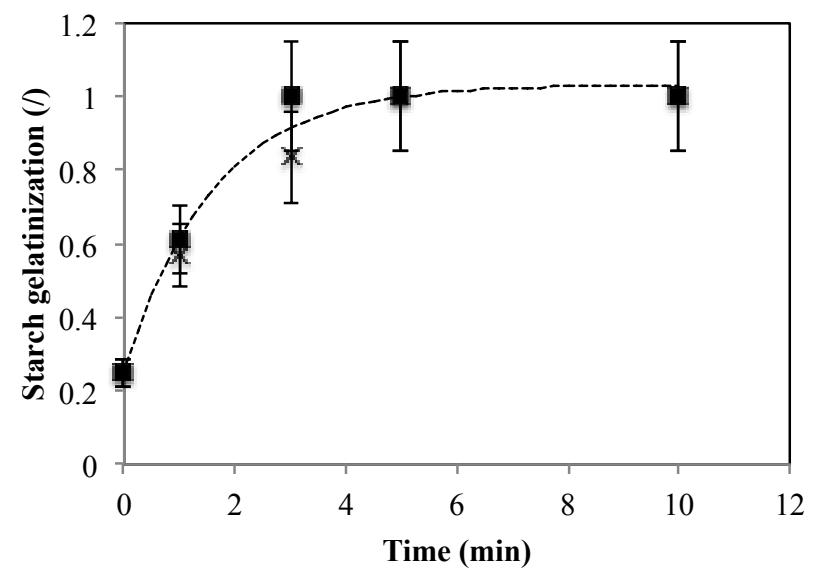

Fig. 2. Changes in the extent of starch gelatinization of wet agglomerates of durum wheat as a function of the time of the cooking stage, at different initial water contents $(\square 0.32 \mathrm{~g} / \mathrm{g}$ dry matter and $\mathrm{x} 0.48 \mathrm{~g} / \mathrm{g}$ dry matter) before cooking. The dotted lines are the first order equation used to fit the experimental data.

This article is protected by copyright. All rights reserved. 


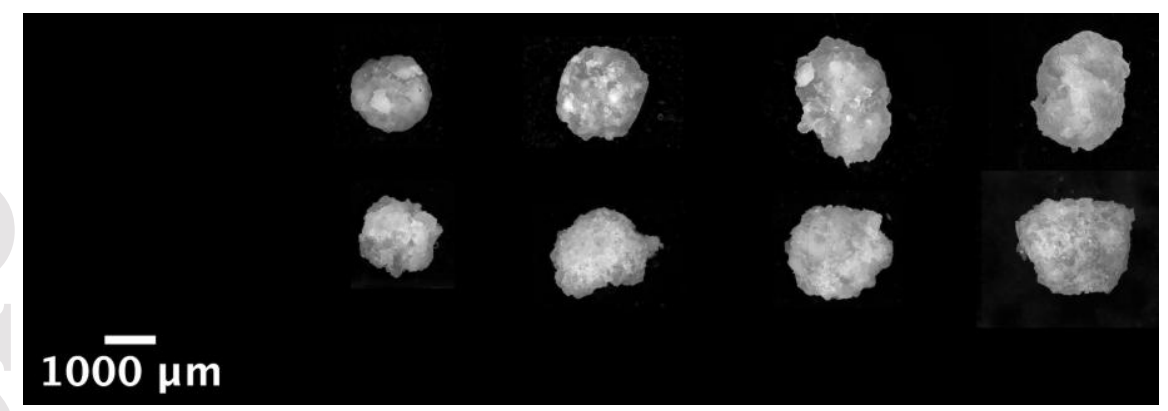

Fig. 3. Microstructure of the wet agglomerates of durum wheat semolina as a function of the steam cooking times (left to right: $1,3,5$, or 10 minutes), at different initial water contents (top row $=0.32$ and bottom row $=0.48 \mathrm{~g} / \mathrm{g}$ of dry matter).

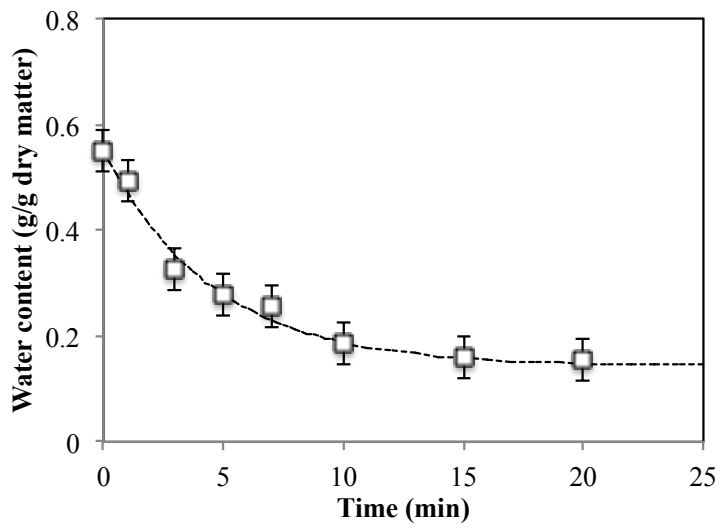

a)

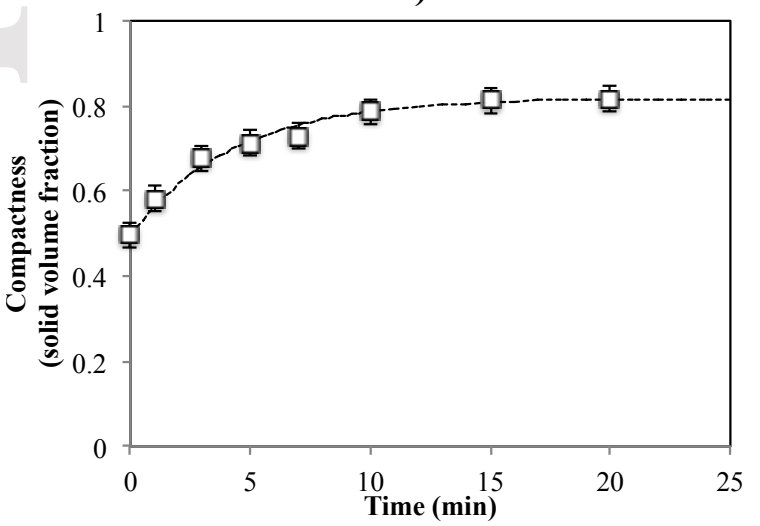

b)

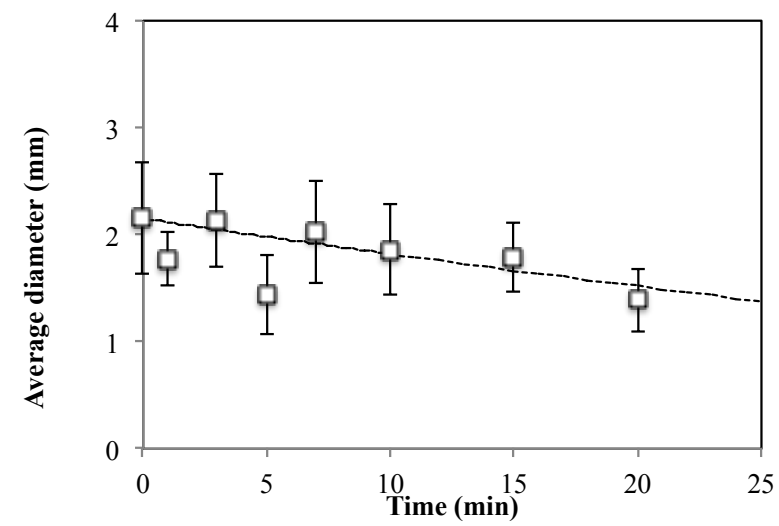

c)

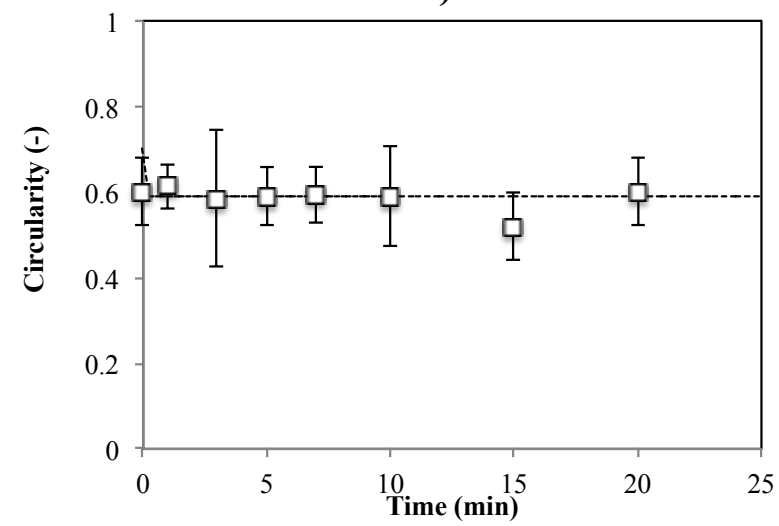

d)

Fig. 4. Changes in water content (a), compactness (b), average diameter (c), and circularity (d) of wet agglomerates of durum wheat as a function of the time of the drying stage at $50^{\circ} \mathrm{C}$. The dotted lines are the first order equation used to fit the experimental data.

This article is protected by copyright. All rights reserved. 


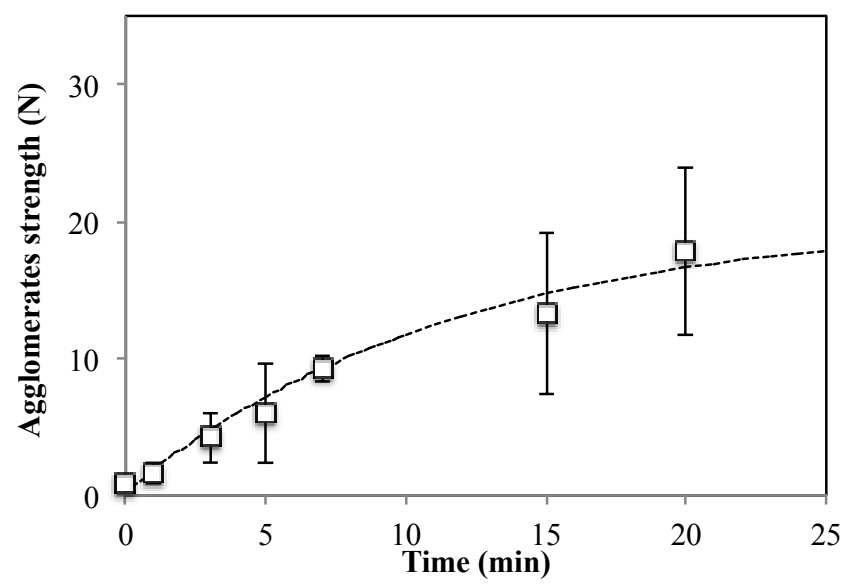

Fig. 5. Changes in the mechanical strength of wet agglomerates of durum wheat as a function of the time of the drying stage at $50^{\circ} \mathrm{C}$. The dotted line is the first order equation used to fit the experimental data.

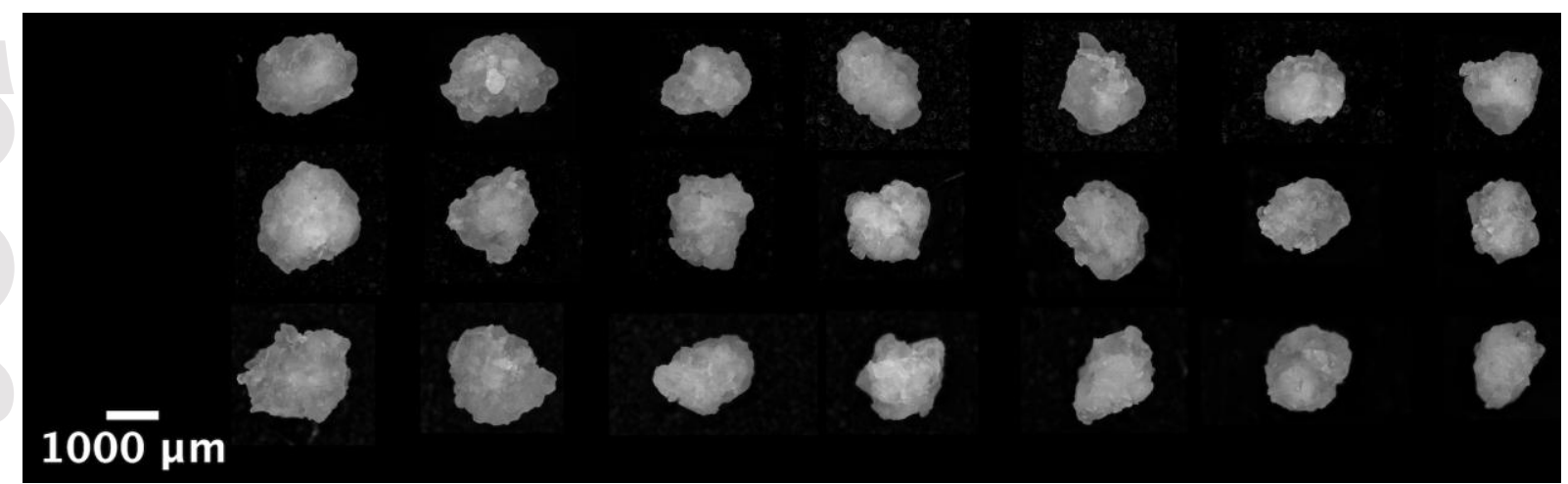

Fig. 6. Microstructure of the wet agglomerates of durum wheat semolina as a function of the drying times (left to right: $1,3,5,7,10,15$, or 20 minutes), at different drying temperatures (top to bottom: 50,70 , or $\left.90^{\circ} \mathrm{C}\right)$. 


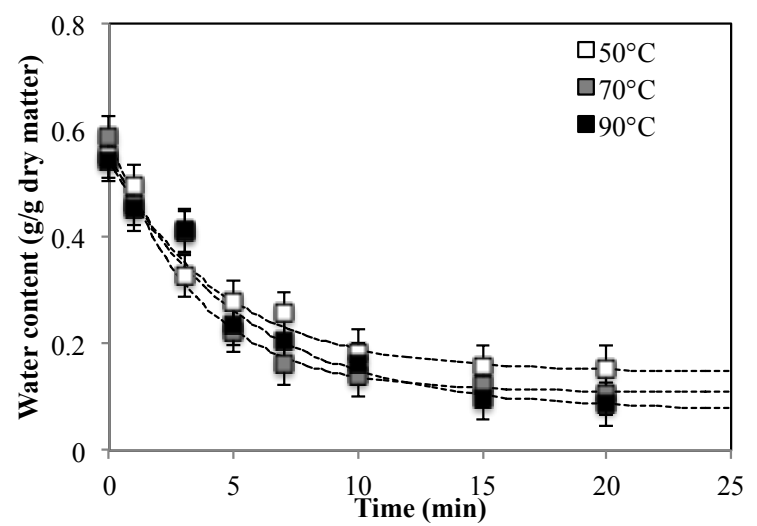

a)

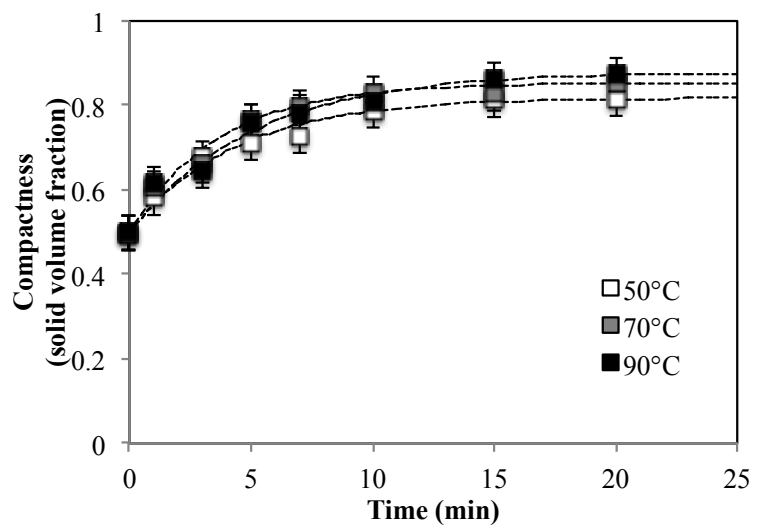

b)

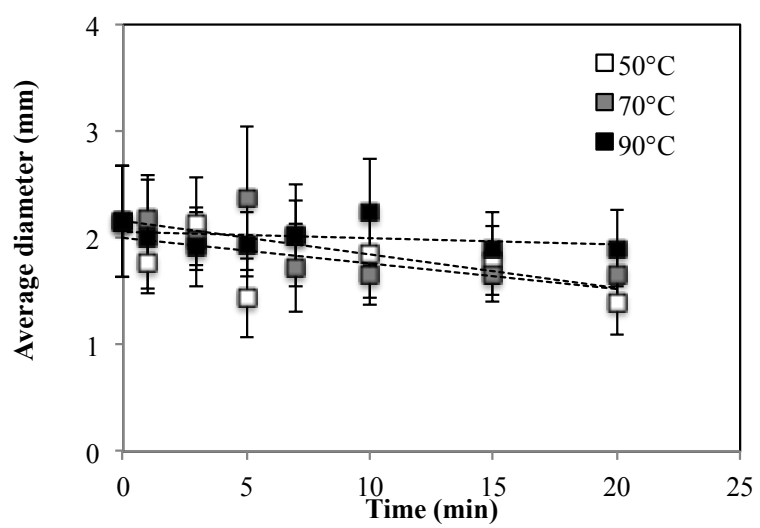

c)

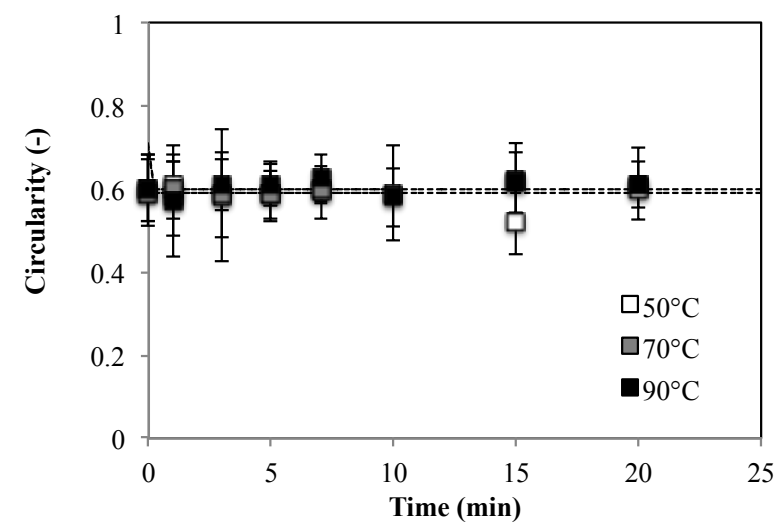

d)

Fig. 7. Impact of the drying temperature $\left(50,70\right.$, or $\left.90^{\circ} \mathrm{C}\right)$ on the changes in water content (a), compactness (b) of wet agglomerates of durum wheat as a function of the time of the drying stage (at $50 \%$ relative humidity). The dotted lines are the first order equation used to fit the experimental data.

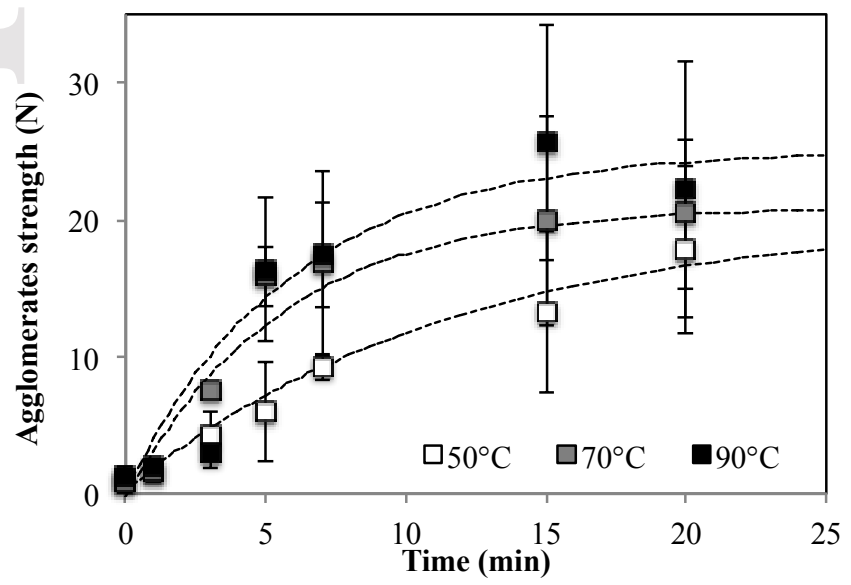

Fig. 8. Impact of the drying temperature $\left(50,70\right.$, or $\left.90^{\circ} \mathrm{C}\right)$ on the changes in the mechanical strength of wet agglomerates of durum wheat as a function of the time of the drying stage. The dotted line is the first order equation used to fit the data. 


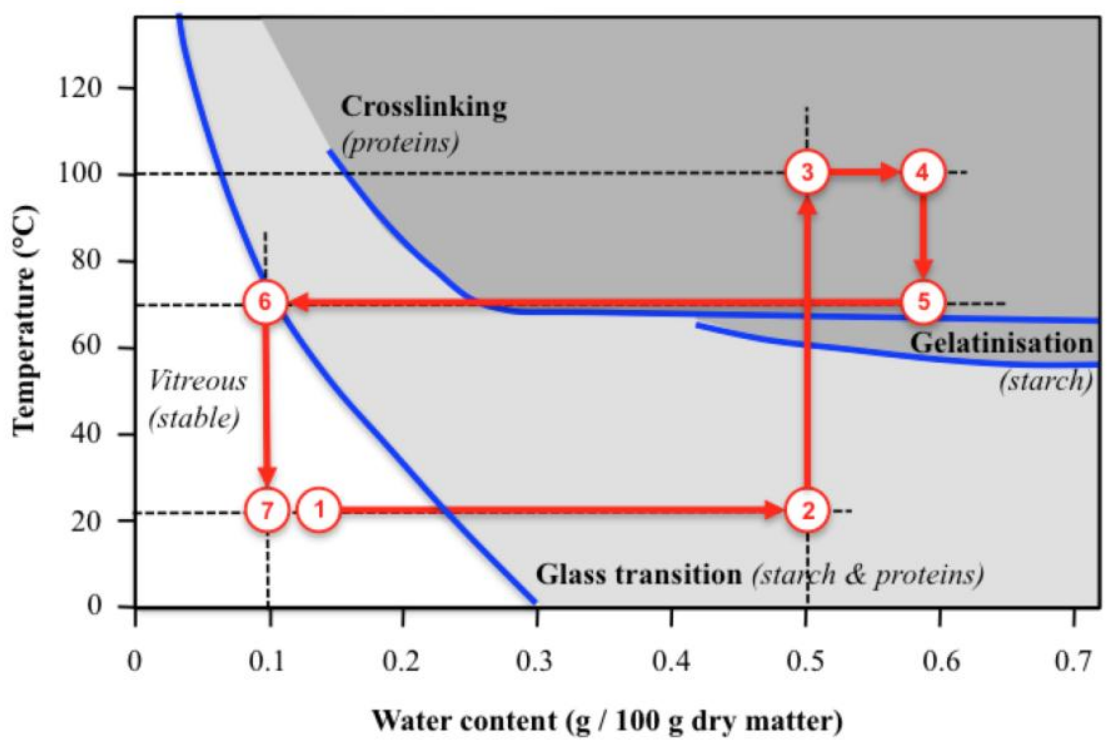

Fig. 9. Schematic representation of the "temperature - water content" state diagram for durum wheat semolina (adapted from Abecassis et al., 2012). Technological way to describe couscous grains processing on the state diagram for durum wheat semolina. With native semolina (1), agglomeration and rolling stages $(1 \rightarrow 2)$, wet agglomerates $(2)$, steam cooking stage $(2 \rightarrow 4)$, drying stage at $70^{\circ} \mathrm{C}$ $(5 \rightarrow 6)$, and final dried grains $(7)$.

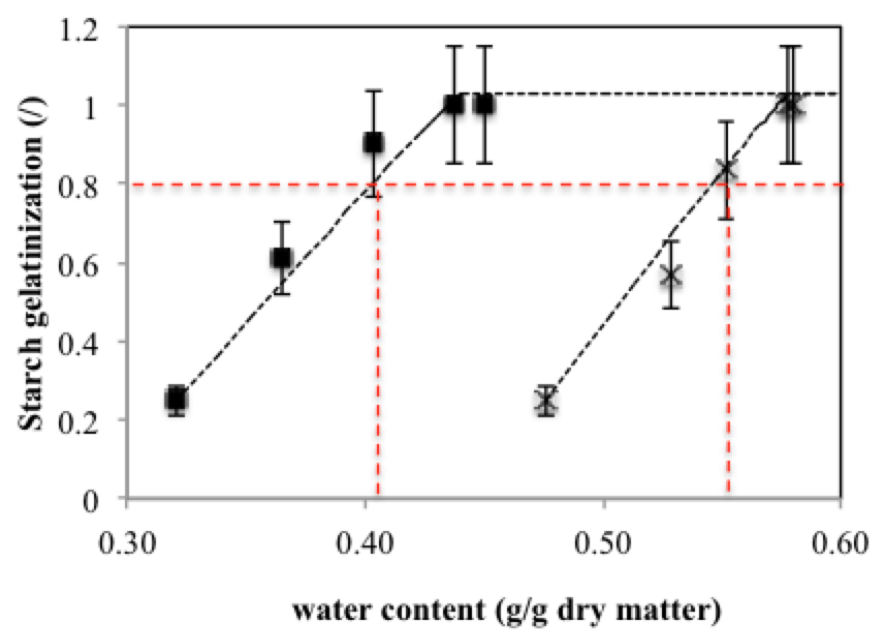

Fig. 10. Extent of starch gelatinization as a function to the water content. a) water addition level of $0.32 \mathrm{~g} / \mathrm{g}$ dry matter $\mathrm{b}) \times$ water addition level of $0.48 \mathrm{~g} / \mathrm{g}$ dry matter. 


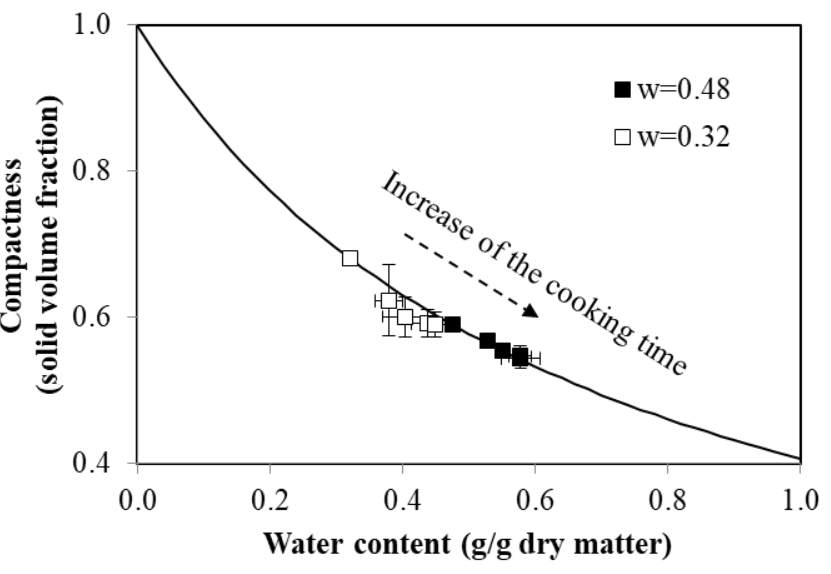

(a)

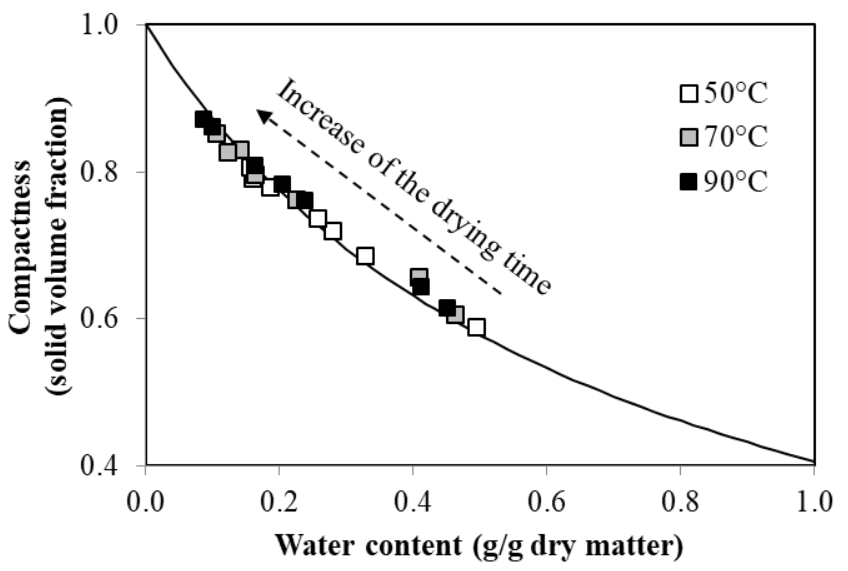

(b)

Fig. 11. Hydro-textural description (compactness vs. measured water content) of the wet grains of durum wheat semolina during the steam cooking stage (a) at different water contents $(0.32$ or $0.48 \mathrm{~g} / \mathrm{g}$ dry matter) and during the drying stage (b) at different drying temperatures $\left(50^{\circ} \mathrm{C}, 70^{\circ} \mathrm{C}\right.$, or $\left.90^{\circ} \mathrm{C}\right)$. The saturation curve is the continuous line.

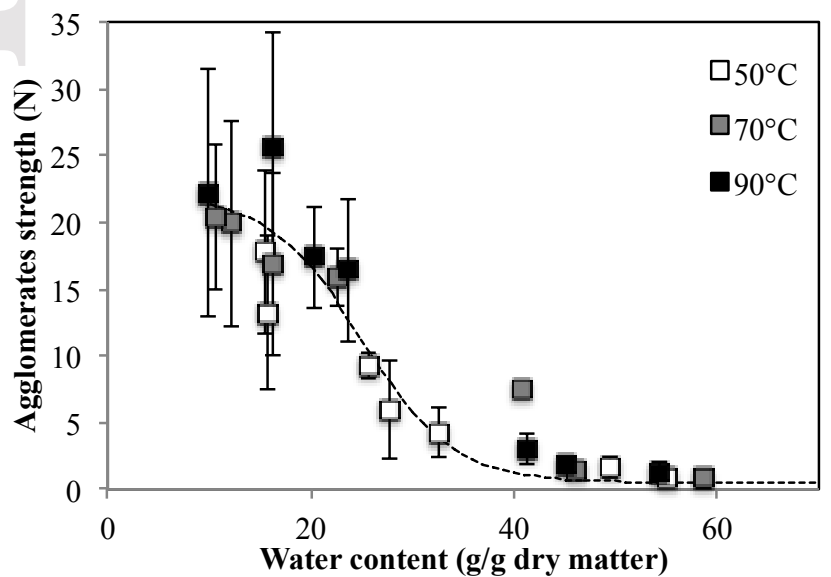

Fig. 12. Impact of the drying temperature $\left(50,70\right.$, or $\left.90^{\circ} \mathrm{C}\right)$ on the changes in the mechanical strength of wet agglomerates of durum wheat as a function of the water content of the drying stage. The dotted line is the logistic model. 


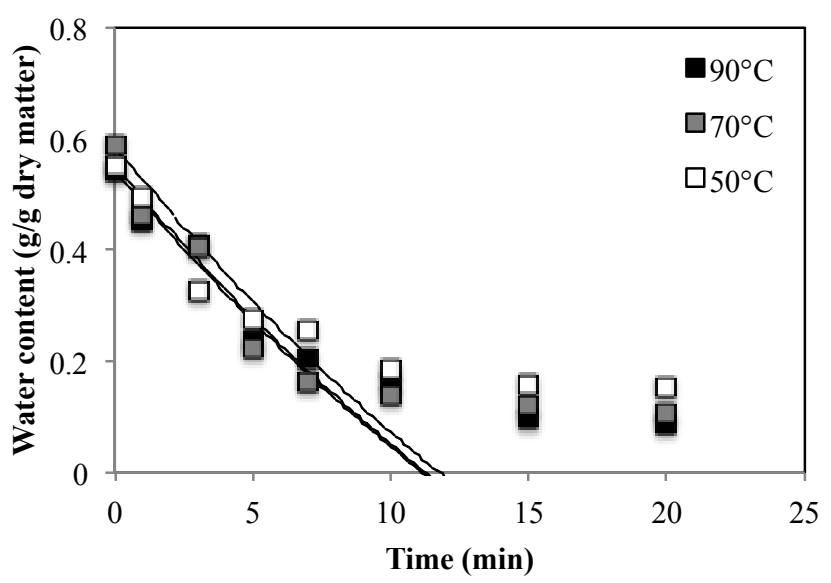

Fig. 13. Analytical model (the dotted line) to describe the kinetic of dewatering as a function of the drying temperature $\left(50,70\right.$, or $\left.90^{\circ} \mathrm{C}\right)$. 